\title{
Las oraciones ambiguas: aportes lingüísticos para su tratamiento pedagógico
}

\author{
Jorge Esquivel Villafana \\ Universidad Nacional Mayor de San Marcos \\ Esquivel_jorge5@hotmail.com
}

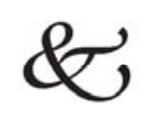

\begin{abstract}
Resumen
El presente trabajo se propone abordar la manera en que los avances de la linguiística teórica pueden ser aplicados en la enseñanza de la gramática, específicamente del nivel sintáctico de la lengua. A modo de ejemplo se analizará el caso de las oraciones ambiguas en el español.

Palabras claves: Linguíística, enseñanza de la gramática, sintaxis.
\end{abstract}

\begin{abstract}
The present work proposes to approach the way in which the advances of the theoretical linguistics can be applied in the teaching grammar, specifically of the syntactic level of the language. As an example, will be analyzed the case of the ambiguous sentences in Spanish.
\end{abstract}

Key words: Linguistics, teaching of the grammar, syntax.

\section{Introducción}

La tarea educativa en la enseñanza secundaria en la especialidad de Lenguaje y Literatura supone el desarrollo del programa oficial en lo que significa el abordaje de los contenidos de elocución, audición, redacción, lectura, gramática, literatura, análisis de imágenes y razonamiento verbal. La enseñanza de la gramática precisamente pretende desarrollar en el alumno la capacidad de reflexión sobre el sistema estructural y funcional de la lengua, ello exige una gran dosis de creatividad y capacidad crítica para echar mano de las innovaciones teóricas que ofrece la ciencia linguiística en favor del proceso pedagógico sin menoscabar la inteligibilidad ni la efectividad de los contenidos ofrecidos. 


\section{Objetivos}

Desde el mirador de la teoría generativa, nos permitiremos sugerir el modo de enfocar el análisis sintáctico de las oraciones ambiguas y demostrar que su presentación mediante el empleo de los diagramas arbóreos correspondientes ofrece expectativas de gran rentabilidad pedagógica.

\section{Evaluación de las gramáticas}

De acuerdo con los objetivos ofrecidos, es lícito reconocer que la gramática tradicional, con su propuesta de método prescriptivo acerca del correcto empleo de la lengua, lejano de lo que significa el análisis y reflexión acerca del sistema linguiístico, queda largamente superada; resta por examinar los alcances y aportes de las gramáticas modernas -estructural y generativa- desarrolladas históricamente en el orden presentado.

La gramática estructural (1916), inspirada en el empirismo, le da recién el carácter científico al estudio del lenguaje. La base de análisis es el enfoque descriptivo, el que de la mano con la aplicación del método inductivo analiza detalladamente el corpus linguiístico mostrando detalladamente el inventario de los elementos constitutivos, distintivos y funcionales de cada uno de los niveles de la lengua, con cierto rigor científico, pero con una marcada limitación, la cual es ceñirse solamente a los elementos que el corpus ofrece porque, por principio, sólo reconoce como fuente del conocimiento linguíístico los elementos de la experiencia, esto es, los productos del habla recogidos en un corpus, de allí el rótulo de taxonómica con que se la caracteriza.

La gramática generativa (1957), inspirada en el racionalismo, supera el estado taxonómico de la gramática estructural, emplea el método deductivo de análisis y se centra en la descripción y explicación de los fenómenos linguiísticos. Para ello, trasciende el corpus linguístico o el conjunto de oraciones producidas por el hablante y recogidas por el linguiista para orientar su atención al mecanismo que lo produjo, esto es, el conjunto de reglas interiorizadas por el hablante que le permiten producir no sólo las oraciones del corpus sino las posibles oraciones de la lengua, constituyéndose en el modelo que mejor refleja la competencia linguiística del hablante. 
Entre las características más relevantes de la gramática generativa que la distinguieron de la estructural están justamente a) la revalorización del estudio del significado o componente semántico de la lengua, lo que le permitió conseguir mayor rigor en el análisis sintáctico, y b) la consideración de dos niveles de estructura en toda oración (la estructura profunda o latente y la estructura superficial o patente).

La gramática generativa se perfila así como la más adecuada para su aplicación en el análisis de la lengua. Ayuda todavía más el hecho de que haya logrado integrar coherente y sistemáticamente todos los niveles de la lengua en lo que es el concepto de gramática. De aquí que consideremos que se dé por descontada su aptitud para procesar, por ejemplo, las estructuras sintácticas ambiguas, denominadas también -en paralelo- por su doble interpretación, las que de algún modo constituyeron el talón de Aquiles de la gramática estructural. Asimismo, constituye también una ventaja a nivel pedagógico la presentación de la estructura sintagmática de la oración mediante esquemas arbóreos que ahora con el modelo de Rección y Ligamiento, al reconocer más de un nivel en la proyección del sintagma, se gana en versatilidad y adecuación empírica en la expresión de las relaciones de jerarquía y dependencia establecidas entre los constituyentes de la oración.

De acuerdo con el modelo de X barra del generativismo, la oración es concebida como una estructura cuyos constituyentes están dispuestos en dos niveles jerárquicos diferentes expresados en esquemas arbóreos que expresan satisfactoriamente las relaciones internas que mantiene cada constituyente con los demás (Fernández y Anula, 2004). Cada una de las categorías léxicas (N(ombre), Adj(etivo), V(erbo), Prep(osición) y Adv(erbio) funciona como núcleo y da lugar a la proyección máxima, el sintagma, como se aprecia en (1).

(1)

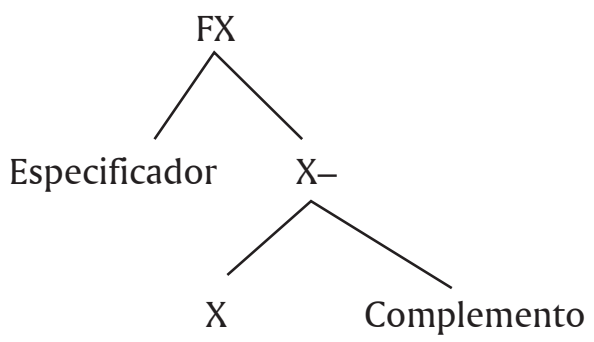


$\mathrm{X}$ se constituye en el núcleo de la frase o sintagma. En la primera proyección del núcleo hallamos a X (X prima) y, en la segunda proyección, la máxima, el sintagma o frase, FX. La presencia del núcleo es obligatoria, los especificadores y complementos son opcionales. La oración recibe la misma consideración que una categoría lexical; tiene, por tanto, un núcleo (Flex); un especificador (la FN-sujeto) y un complemento (la FVpredicado). Cabe agregar que el núcleo de la oración o sintagma oracional, Flex, definido por los rasgos de $[ \pm \mathrm{T}$ (iempo) $]$ y $[ \pm$ Conc(ordancia) $]$ lleva información acerca del tiempo y modo (categorías exclusivamente verbales) y de persona y número (categorías verbonominales), lo que le permite constituirse en el elemento cotejador de la concordancia oracional.

(2)

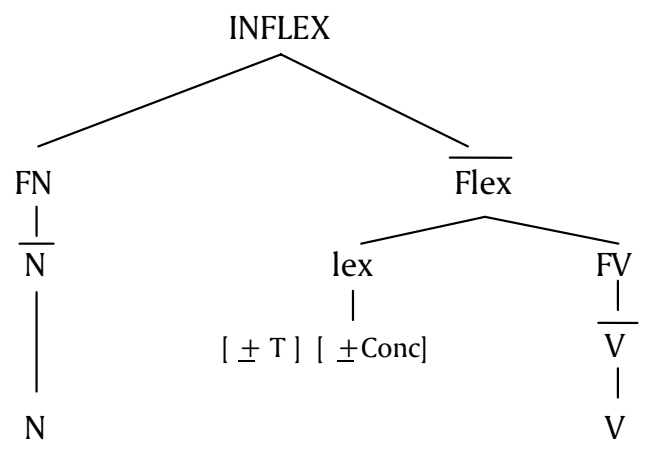

\section{Las oraciones ambiguas}

De acuerdo con lo antedicho, las oraciones ambiguas o portadoras de una doble interpretación semántica, son analizadas como el caso de un enunciado con una estructura superficial y dos o más estructuras profundas. Así, por ejemplo, la frase "la búsqueda de los estudiantes" proyecta dos significados oracionales paralelos:

(3) a. Los estudiantes buscaban algo

b. pro buscaban a los estudiantes

La ambiguiedad sintáctica proyectada puede ser descrita apelando a consideraciones de orden semántico donde la FN "los estudiantes" 
puede ser analizada con el rol de agente en (3a) o de paciente (3b) de la acción predicativa; o a las de orden sintáctico donde las funciones gramaticales de sujeto u objeto directo se expresan en términos de relaciones categoriales y configuracionales (Fernández y Anula, 2004 ). Así, para la interpretación de (3a) se propone la representación bosquejada en (4).

(4)

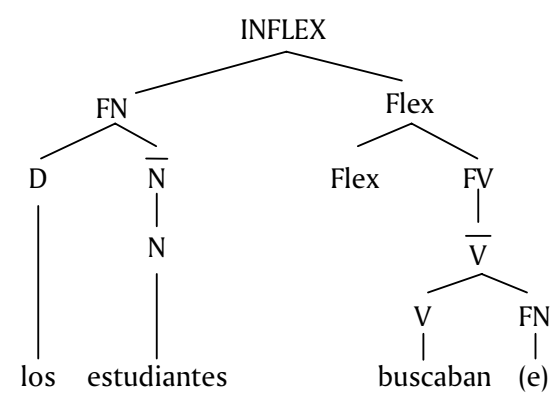

Según vemos, el sujeto o el especificador de oración, dominado directamente por INFLEX, está representado por una categoría frasal plena, explícita, la FN "los estudiantes". El predicado o el complemento de Flex está representado por la FV "buscaban (e)" cuyo núcleo es el verbo "buscaban". La FN que funciona como el objeto directo vacío o nulo, representada por la categoría (e), equivalente al significado de 'algo' o 'alguien,' aparece dominada por V, pues, a tenor de la teoría, el nódulo $\mathrm{V}$ prima domina el verbo y sus complementos. Para la interpretación de la oración (3b) se propone la siguiente representación esquemática.

(5)

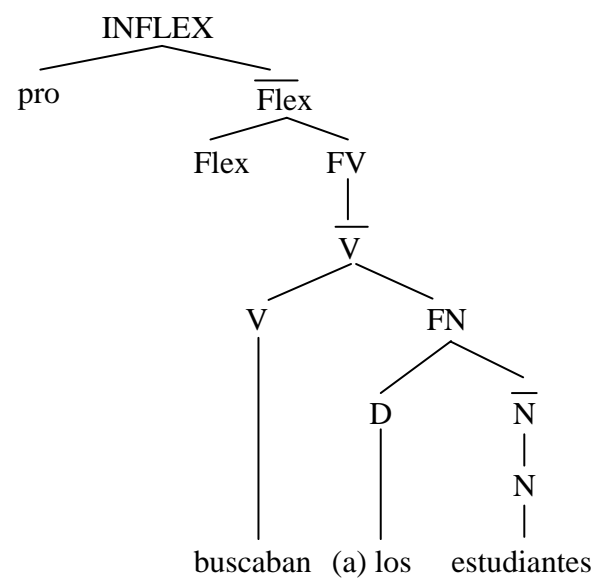


El sujeto o especificador de oración está expresado por la forma "pro"; esto, por cuanto el concepto de sujeto es una categoría obligatoria en esta teoría y si éste carece de carga fonética "como en el caso que analizamos" es representado, en virtud del principio de proyección extendido (Fernández y Anula, 2004) por la categoría vacía de pro (minúscula). Así, la categoría frásica FV "buscaban a los estudiantes" se constituye en el predicado de la oración donde la FN "a los estudiantes", dominada por el nódulo $\mathrm{V}$, es reconocida como el OD.

En el análisis de la oración ambigua se asume que las estructuras profundas que las subyacen han resultado en una misma estructura de superficie, lo que suele ocurrir en las sintaxis de las lenguas por cuanto el número de oraciones que uno puede significar, en términos semánticos, es infinito, mientras que el número de estructuras formales que le pueden servir de vehículo es finito, de ahí que dos o más posibilidades significativas paralelas puedan coincidir en una misma secuencia estructural terminal, o sea, en una misma estructura superficial interpretable fonológica y fonéticamente (Niño Rojas, 2002).

De igual modo, en un enunciado como "el entrenador le dijo al corredor que necesitaba descansar" (Fernández y Anula, 1995: 384), la ambiguiedad reside en el hecho de que la cláusula subordinada "que necesitaba descansar" puede ser interpretada como a) una completiva sustantiva-OD, dependiente, por tanto, del nódulo V, de acuerdo con la naturaleza sintáctica del verbo principal transitivo "dijo" (véase (6)).

(6)

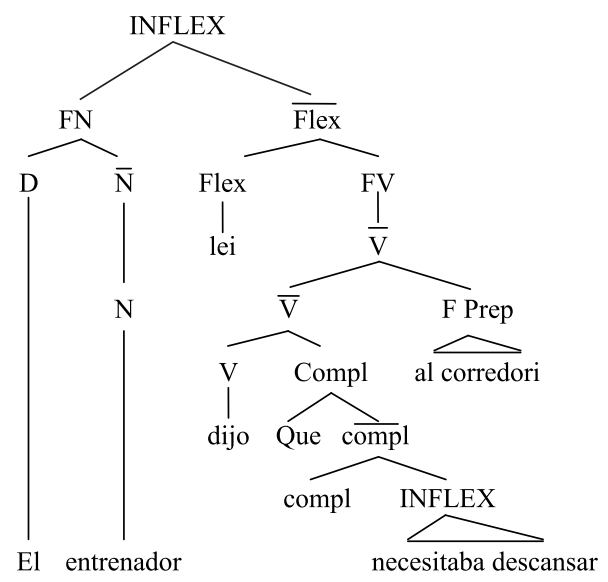


$\mathrm{O}$, como b), una cláusula relativa restrictiva complemento del núcleo nominal del objeto indirecto ${ }^{1}$, dependiente, por tanto, del nódulo $\mathrm{N}$, de acuerdo con el esquema configuracional reservado para el complemento especificativo del núcleo nominal(izado) "corredor", como se aprecia en el siguiente diagrama.

(7)

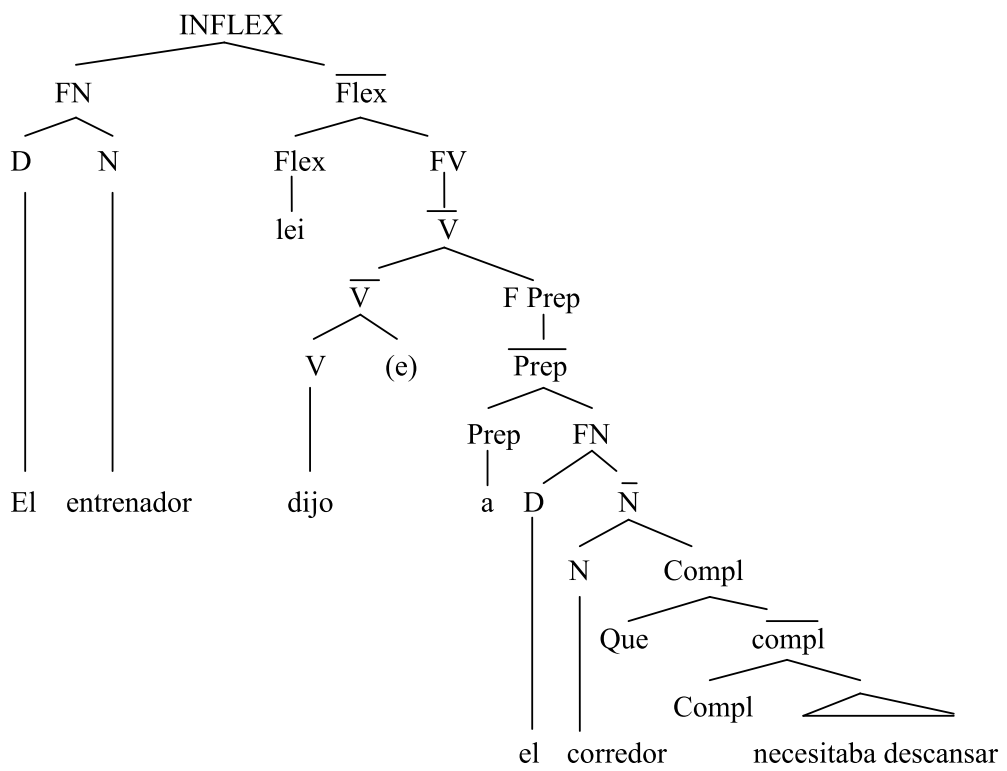

Es necesario destacar que las interpretaciones paralelas de la oración de superficie ofrecidas por el componente semántico conllevan sus respectivas descripciones estructurales, lo cual permite evidenciar, además de los diferentes niveles jerárquicos, las diferentes funciones que cumplen las unidades sintagmáticas involucradas en las oraciones, procedimiento analítico que difícilmente pueda ser superado ubicándose en un mirador diferente al de la teoría generativa.

1 Nótese, además, que la FN-objeto directo está representada por la categoría vacía (e). De acuerdo con lo expresado anteriormente respecto a la representación de las categorías vacías en esta gramática, ellas suelen ser representadas por pro o PRO respectivamente, según reciban o no la marca de caso en la posición de sujeto. Con un afán diferenciador, cuando ésta asume una función diferente -la de objeto directo vacío o nulo, por ejemplo- es representada por (e) (del inglés “empty”), a la usanza de Hernanz y Brucart (1987). 


\section{Epílogo}

Como se pudo apreciar, el tratamiento sintáctico de las oraciones ambiguas encuentra en la gramática generativa el soporte teórico requerido para su feliz y riguroso abordaje. Sus interpretaciones paralelas logran ser caracterizadas mediante sendos diagramas arbóreos, los cuales permiten visualizar aspectos relacionales abstractos establecidos entre los constituyentes de oración, con los que el análisis sintáctico, creemos, gana en precisión y rentabilidad pedagógica.

\section{Referencias bibliográficas}

CHOMSKY, Noam (1988): La nueva sintaxis. Teoría de la rección y el ligamiento. Buenos Aires: Ediciones Paidós.

FERNÁNDEZ LAGUNILLA, M. y ANULA REBOLLO (1995): Sintaxis y cognición. Introducción a la gramática generativa. Madrid: Editorial Síntesis.

FERNÁNDEZ LAGUNILLA, M. y ANULA REBOLLO (2004): Sintaxis y cognición. Introducción a la gramática generativa. 2da. edición. Madrid: Síntesis S.A.

HERNANZ, M.L. y BRUCART, J. M. (1987): La sintaxis. Barcelona: Editorial Crítica S.A.

LAMIROY, Béatrice (1991): Léxico y gramática del español. Estructuras verbales de espacio y tiempo. Barcelona: Editorial Anthropos. Promat, S. Coop. Ltda.

NIÑO ROJAS, Víctor Miguel (2002): Semiótica y lingüística aplicadas al español. Colombia: Ecoc ediciones.

SAUSSURE, Ferdinand (1985): Curso de lingüística general, traducción de Mauro. España: Editorial Planeta. 